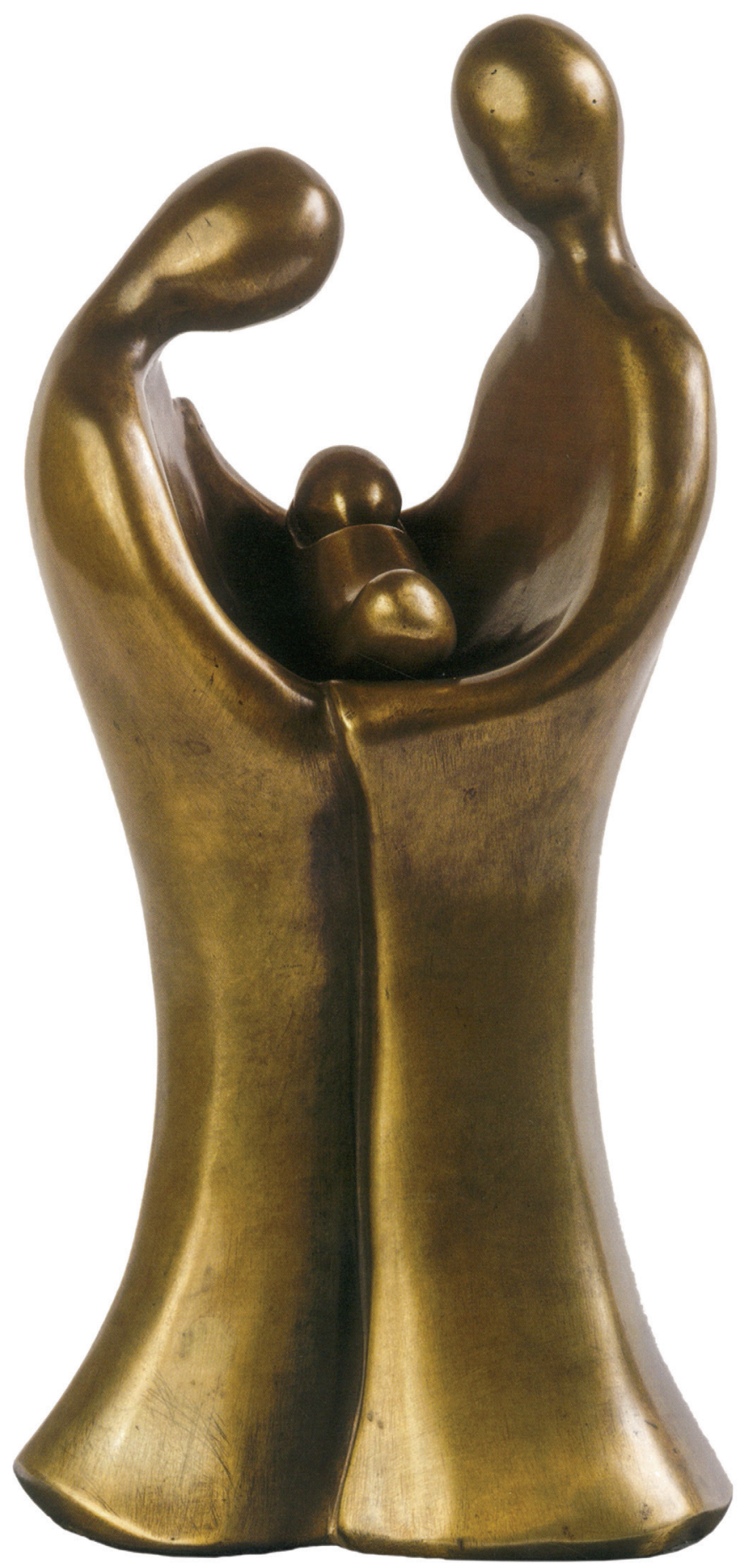





\section{LA CONSOLIDACIÓN DE LA CELEBRACIÓN NAVIDEÑA COMO PRÁCTICA SOCIORRELIGIOSA \\ EN EL SIGLO XX}

El proceso de creación, difusión, reproducción y apropiación del texto que fundamenta la devoción al misterio de la encarnación y por extensión al Niño Dios, evidencia una compleja dinámica social que a través del tiempo ha permitido su permanencia en el campo religioso y su incursión en el ámbito cultural. De ahí que sea pertinente entender la forma como logró instaurarse en los recuerdos más perdurables de todos aquellos que hoy prolongan su práctica en familia y en comunidad, dado que ni las profundas disputas ideológicas que han caracterizado la historia del país, ni las intensas luchas del bipartidismo liberal-conservador que desde el siglo XIX polarizaron con firmeza a la población ${ }^{1}$, impidieron que las personas de cualquier afinidad política o condición social, unidos en grupos familiares, sociales, parroquiales o simplemente de vecinos y amigos, abrazaran la tradición de celebrar la Novena.

Sin distinción, su esencia se fue abriendo paso, apadrinada por instituciones como la escuela, la Iglesia y la familia, unidades básicas en la gestación, instrucción y desarrollo de pautas de comportamiento y valores morales. En este orden de ideas, se analizan las particularidades históricas que hicieron posible la permanencia de la Novena del Niño Dios y su consolidación en el

1 En el siglo XIX, como en muchos otros países de América Latina, la población de Colombia se dividió en dos grupos que en apariencia estaban claramente diferenciados: el liberalismo, que "fue o pretendió ser la representación política" de "grupos de comerciantes, masas de indígenas y de esclavos [...], artesanos, propietarios medios e intelectuales, [...] a través de la implantación de las doctrinas de libre comercio, abolición de la esclavitud, circulación de la propiedad territorial, secularización del Estado, etc.". Por su parte, el conservatismo "se presentó como el partido del orden, de la defensa de la civilización contra la barbarie representada en los cambios, [alineándose] dentro de un gran debate en el mundo occidental, al lado de la Iglesia Católica” (Tirado, 1996, párr. 6). 
tiempo como una práctica sociorreligiosa de gran arraigo cultural dentro del marco ético y moral del momento, y su posicionamiento en la memoria colectiva de las familias colombianas.

\section{Una nueva forma de experimentar la religiosidad}

Colombia recibió el siglo XX en medio de la más larga y cruenta de las guerras civiles desatadas por las ambiciones partidistas de liberales y conservadores: la llamada Guerra de los Mil Días. Las consecuencias de este conflicto se pueden resumir en la devastación económica, la agudización de la deuda externa por los gastos militares, la destrucción de buena parte de las todavía incipientes infraestructuras e industrias, la pobreza y miseria de miles de colombianos y, principalmente, la pérdida de una porción del territorio nacional con la separación del departamento de Panamá el 3 de noviembre de 1903 (Santos, 2004b). Como señala el periodista e historiador Enrique Santos Molano, el XX fue el siglo "contradictorio de la paz y de la violencia”, que generaron infinidad de cambios y vicisitudes en la vida del país: "inició con las promesas de bienaventuranza pactadas a bordo del vapor Wisconsin, que pusieron fin a la guerra de los Mil Días, y terminó con la oleada de violencia generada por la caótica mezcla de subversión, paramilitarismo y narcotráfico" (Santos, 2004a, párr. 1)².

Uno de los principales cambios fue el desplazamiento humano del campo hacia la ciudad, en donde se fueron concentrando las industrias y otros procesos productivos que necesitaban mano de obra. A finales del siglo XX grandes masas de gentes se encontraban en contacto con nuevas tecnologías y nuevos modos de vivir. Esto derivó paulatinamente en un cambio de la lógica predominante años atrás: una sociedad en la cual prevalecía la cultura rural comunitaria, pasó a un ambiente y a espacios técnicos, industrializados y urbanos, produciendo una transformación de la "psicología humana", investigada y

2 Agrega este autor que "de todas las lecciones del pasado tenemos algo que aprender. Por ejemplo, la Guerra de los Mil Días. Después de tres años de guerra y cien mil muertos, buscaron un acuerdo que pusiera fin al conflicto, sin que hubiera vencedores ni vencidos concretaron las paz, sin condiciones depusieron las armas, el Gobierno respetó las garantías que se habían acordado y el país entró en una era de paz casi absoluta que duró cuarenta años y que le permitió a Colombia un desarrollo económico, social y cultural que sólo se puede medir comparando las condiciones de atraso en todos los órdenes que vivía el país al comenzar el siglo XX" (Santos, 2016, p. 8). 
sistematizada por Marcel Mauss y Milton Friedman, tema retomado por Sabino Acquaviva. Desde la sociología, la economía, la psicología, la historia, la cultura y la religión los investigadores de la sociología del hecho religioso consideran que entre las consecuencias sociales de las transformaciones técnicas e industriales se encuentra un continuo retroceso de la religiosidad, porque aquella lógica se ha impregnado de conceptos derivados de la más reciente evolución técnico-científica. Acquaviva aclara en las notas de su investigación que hasta en "las élites que más han asimilado los parámetros científicos, la religiosidad parece haber ido decayendo, y esto se ha realizado justamente porque los parámetros científicos y técnicos prevalecen sobre los religiosos, y digámoslo así, naturales" (Acquaviva, 1972, p. 274).

El hombre del ambiente rural, así como del urbano anterior a la industrialización, vivía a otro ritmo, en otro espacio y otro tiempo, en una unidad en la cual se conectan la actividad física e intelectual. Sin embargo así "como una nueva visión religiosa puede cambiar el sentido del tiempo y del espacio, un nuevo sentido del tiempo y del espacio puede cambiar la visión religiosa" (Acquaviva, 1972, p. 270). De este modo, tres revoluciones industriales, las máquinas y la sociedad industrial se convierten en mitos para el hombre, se da un cambio de sentido en las culturas y religiones tradicionales, una "paganización y descristianización” para algunos sociólogos, o una "desacralización”, como señala Acquaviva para dar una acepción análoga: "La significación atribuida a la crisis de la religión en la edad contemporánea es, en el fondo, el problema que de manera diversa condiciona el comportamiento de cada hombre que vive en la moderna sociedad" (1972, pp. 13-14). Se trata de una dificultad real, ante la cual varias generaciones se han sentido cuestionadas frente a las consecuencias de su posición, consciente o inconsciente, expresa o reflexiva, negativa o positiva ante la crisis religiosa que acompaña el proceso de industrialización.

El lenguaje, el arte, la ciencia, la historia, la cultura y la sociedad técnica y científica actuales son muy significativos para los investigadores respecto al impacto religioso en la sociedad industrializada. Muchos afirman el efecto de dispersión de la carga emotiva y sentimental y la esterilización de las emociones y actitudes cognoscitivas frente a la experiencia religiosa. Retomando a Cassirer, cambia la lógica, el lenguaje se modela según la vida y la psicología; se racionalizan y pierden fuerza los valores religiosos (Acquaviva, 1972, pp. 272-273). Esta afirmación parece contradictoria con las actividades y las expresiones de fe a través de la historia. Desde las culturas más antiguas, el arte y el lenguaje estaban más unidos a la religión, lo cual ha variado desde los años sesenta y setenta del siglo XX, por un arte conceptual y reflexivo que 
hace énfasis en las ideas sin necesidad de expresiones materiales concretas (Fargas, 2008).

En contradicción con las investigaciones anteriores, aun cuando hoy se vive en medio de ritmos acelerados en un mundo que parece desarticulado en medio del movimiento permanente y aligerado del hombre en cualquier lugar, tiempo y circunstancia ${ }^{3}$, se da, sin embargo, la experiencia de lo sacro. Acquaviva (1972) presupone "el reconocimiento de la validez del concepto de adaptación del hombre al ambiente en que vive, y juntamente su capacidad de actuar sobre dicho ambiente" (p. 269). A medida que la persona tiene el mayor manejo y dominio de las tecnologías, en lo que parecería una automatización de la producción y del mismo hombre, existe una sensibilidad y percepción que "dejan espacio para una profundización interior y para el sentimiento" (Friedmann citado por Acquaviva, p. 270), para vivir tradiciones, determinadas acciones, lugares y tiempos que se ordenan a lo divino de una manera que cae fuera del ámbito de lo habitual ${ }^{4}$.

Todo hombre tiene la experiencia de lo sagrado y lo profano: en la conciencia y acciones en favor de la dignidad humana se manifiesta y simboliza lo sagrado. Negar esta manifestación es lo que los investigadores de la sociología religiosa denominan desacralización. Hoy es más difícil reconocer esa presencia sagrada por la influencia de la ciencia y la tecnología. Sin embargo la aceptación del acontecimiento original de la encarnación es el fundamento

3 El escritor Amin Maalouf pide la conciencia de que "hemos estrenado una nueva época. La globalización ha derrumbado las fronteras políticas y económicas propiciando que la economía sea el auténtico soberano de nuestros destinos. Como consecuencia. el fenómeno migratorio modifica el mapa de la convivencia [...]. Hoy, la diversidad es un dato de nuestra realidad planetaria. Aceptar esta realidad plural es el primer paso para construir una identidad personal y colectiva acorde con esta nueva circunstancia" (citado en Aranguren, 2016, pp. 11-12).

${ }^{4}$ En ese sentido, De Roux dice sobre la realidad colombiana que lo que vivimos "no es una crisis religiosa, es una ausencia muy honda de lo que significa la dignidad humana [...] Yo la llamo una crisis espiritual, pero es una crisis antropológica, sociológica, psicológica” (Ocampo, 2016, pp. 76-77). En la coyuntura nacional e internacional actual, la Compañía de María "La Enseńanza”, propició una reflexión conjunta mundial sobre los elementos que dan identidad y valor al proyecto educativo de la Compañía en el mundo. Estos criterios se dirigen hacia el bien común, la responsabilidad social y ambiental, un desarrollo armónico del ser humano en el universo, la educación integral y por tanto la educación para el desarrollo. La reflexión conjunta permitió interiorizar y sistematizar los fundamentos, las claves y los horizontes en el compromiso de trabajar colectivamente por un mundo más humano y habitable (véase Acosta, 2016, p. 5). 
que permite vivir de manera consciente la experiencia sagrada, la experiencia existencial de la fe (Anton, 2013).

En el periodo contemporáneo, algunas personas no son conscientes de las expresiones con las cuales se manifiestan los avances y cambios de la propia posición humana (que evoluciona y forma parte en la condición ambiental e histórica), ni del influjo que han ejercido sobre nuestras elecciones la tradición invisible del ayer y las opciones de las generaciones que nos han precedido. La integración del individuo consigo mismo en la conciencia y comunicación a través del lenguaje; es decir, de aquel conjunto de símbolos y signos comunicativos representado por imágenes, sonidos, palabras y creaciones simbólicas y dinámicas de la vida, manifestadas en las letras, el arte, la poesía, la religión y la cultura, se perpetúan en la familia, en la comunidad y en el país, sin límites en el espacio y el tiempo, ni en el pensar y el obrar. Esta es la vida que se manifiesta en las celebraciones de la Novena de Navidad, que trasciende los límites de su ambiente local: el mundo del pasado, del presente y del posible, porque en ese tiempo se desenvuelve la persona humana, por ello aun cuando es temporal, sus efectos perduran en la realidad cotidiana.

Así, aunque se perciba, investigue y analice la crisis e indiferencia religiosa o desacralización en la actual sociedad, la persona humana expresa una voluntad de supervivencia, un deseo de continuidad y de inmortalidad en todas las múltiples formas imaginables, porque la fuerza de la vida, lo sagrado, constituye un dato constante del espíritu humano. Thomas Molnar, "católico" tradicionalista, nos habla en primer lugar de su experiencia religiosa: es ella la que le ha permitido comprender lo sagrado, porque el hombre es incapaz de vivir fuera de la esfera de lo sagrado; todas las religiones postulan y conocen lo sagrado. Molnar incluso concede que tal vez, en esta época desacralizada, lo sagrado "no cristiano" resiste mejor que el cristianismo; porque aquel está más estrechamente ligado a "los fenómenos de la naturaleza, a la simple psicología humana”. Pero "sólo la religión católica enuncia plenamente lo sagrado, y esto en el momento de la Encarnación” (Acquaviva, 1972, pp. 18-19), el evento religioso cultural que convoca a la familia y a la comunidad cristiana para celebrar la vida y la esperanza, la fe y el amor en el Dios hecho hombre.

En estos espacios y tiempos actuales continúa la participación en las fiestas de Navidad y las celebraciones de la Novena del Niño Dios. Acciones comunitarias en las cuales se renueva una realidad con historicidad en la persona de Jesús, el Hijo de Dios, el Salvador. El Dios humanado que nos hermana y nos enseña a ser más humanos. 


\section{La caridad como eje de la acción cristiana: la influencia de las comunidades religiosas femeninas}

Para comienzos del siglo XX, las festividades navideñas tuvieron ciertas características que deben considerarse, no sin antes aclarar que las estructuras éticas y morales predominantes estaban fuertemente marcadas y delimitadas por los preceptos cristianos que desde siglos atrás constituían parte del cimiento del orden social, en el cual las manifestaciones caritativas tuvieron un gran sentido y contribuyeron a que la celebración religiosa del nacimiento del Hijo de Dios lograra trascender para los colombianos.

El papa Pío X, como principal defensor de la formalización de la organización católica, envió una carta al arzobispo Herrera y sus sufragáneos enunciando el profundo gozo que lo embargó al saber que la Conferencia Episcopal celebrada en Bogotá para 1910, se encaminó a profundizar en la importancia de la beneficencia y la caridad en el marco de la acción social de la Iglesia:

Confiamos en que este género de beneficencia popular, definida y explicada con exactitud y recomendada á todos los católicos por nuestro Predecesor León XIII en su Encíclica Graves de communi del 18 de Enero del año 1901, habrá de ser grandemente saludable al pueblo colombiano, en especial si á la activa caridad de los católicos se junta, para comunicarle mayor eficacia, la uniformidad de pareceres y propósitos, y en si en el desarrollo de los trabajos se tiene siempre en cuenta la autoridad de la Iglesia. Convendría, pues, á este fin de fomentar aquellos institutos, ya usados por los católicos y muy propios para aumentar y desarrollar la caridad, como son las sociedades de obreros, las cajas rurales, las asociaciones de mutuo auxilio, las que tiene por objeto acudir á sus miembros en las desgracias que suele ocasionar el trabajo ó favorecer en los obreros el hábito del ahorro, y otros por el mismo estilo, que bajo los auspicios de la Iglesia, se han fundado y sirven eficazmente al alivio de los indigentes. [...] Al implantar entre vosotros, como lo intentáis, la acción católica social, os hacéis, Venerables Hermanos, patronos de una causa insigne, á saber, la causa de aquellos á quienes oprime la adversa fortuna y de quienes, por divino consejo, estáis constituidos en padres y ayudadores. Tened por cierto que cuantos desvelos empleareis en tal causa, estarán bien empleados y que, mereciendo así bien de la Religión 
y de la Patria, representaréis dignamente al Buen Pastor que Pasó HACIENDO EL BIEN (La Iglesia, abril 1 de 1910, pp. 132- 133).

Con el objetivo de propagar y generar mayor arraigo de la fe cristiana, la Iglesia no solo se responsabilizó de la educación pública, sino que estableció en los Estatutos de la Confraternidad de la Doctrina Cristiana, aprobados el 11 de julio de 1906 por el arzobispo Herrera, la necesidad de enseñar uniforme y constantemente el catecismo en la sociedad civil. Las parroquias de la Diócesis de Ibagué son ejemplo de fidelidad en el cumplimiento de la enseñanza de la doctrina; su estructura se basó en la conformación de congregaciones ${ }^{5}$ compuestas por una presidenta, una secretaria, una tesorera, socias activas ${ }^{6}$, honorarias y contribuyentes ${ }^{7}$, que establecieron un modelo pedagógico diseńado para nueve clases divididas de la siguiente manera:

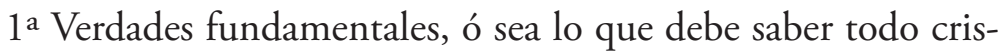
tiano para poder salvarse, dogmas de la Creación, Trinidad, Encarnación, Redención y fin del hombre.

2a Oraciones principales: Credo, Padrenuestro, Ave maría, Salve, Mandamiento de Dios y de la Iglesia, Sacramentos, Señor mío Jesucristo y Yo pecador.

$3^{\text {a }}$ Lo indispensable para confesar bien.

$4^{\mathrm{a}}$ Lo indispensable para comulgar bien.

5a Primera parte de la Doctrina del Padre Astete.

$6^{a}, 7^{a}, 8^{a}$ La segunda, tercera y cuarta partes de la Doctrina del Padre Astete, respectivamente.

9a Ó clase final. Los que ya saben bien toda la Doctrina del Padre Astete, forman una sección superior en la que se les enseña el Catecismo mayor del Papa Pío X (La Iglesia, junio 15 de 1910, p. 297-298).

5 Una institución religiosa dentro de la Iglesia, cuyos miembros consagran su vida a Dios mediante el seguimiento y promulgación de los consejos evangélicos.

${ }^{6}$ Las socias activas son aquellas que dedican una hora a enseñar la doctrina todos los domingos y días festivos.

7 Las honorarias y contribuyentes ayudan mandando niños a la doctrina, y colaboran con alguna cuota mensual para comprar algunos de los regalos que se distribuyen entre estos. 
Para la época, el catecismo del padre Astete se seguía empleando como una herramienta fundamental en la educación cristiana, el cual se enseñaba en todas las escuelas de la república desde hacía ya varias décadas, avalando en ello un esquema de aceptación y reproducción de tal magnitud que era ya costumbre el que las familias conformadas por hombres y mujeres cristianos tomasen dicho catecismo como carta de navegación en la edificación de los principios morales de sus hijos. La trasmisión de las definiciones y pautas de comportamiento que la obra suscitó, ejemplifica lo que sociológicamente se denomina como socialización, concepto referido "a la interiorización de papeles y a la asunción de los mismos, como resultado de un proceso de interacción con los demás y de configuración de la propia identidad, sí mismo o autoconciencia" (Martín, 2000, p. 173)

Uno de los mayores propósitos de la Iglesia para entonces era educar a los niños de los sectores sociales populares, pues se pensaba que la precariedad material y espiritual que poseían podría ser un blanco fácil de perversión a raíz de los argumentos que presentaban quienes afirmaban que la institución religiosa permanecía indiferente ante su situación. Así que, en aras de impedir la depravación de sus almas, se persuade a los católicos de la obligación de crear y mantener escuelas para los hijos del pueblo, en donde se inculque a los niños pobres y a los jóvenes obreros "el santo temor de Dios, la conformidad con su divina voluntad, el amor al trabajo, la obediencia [...], y la caridad, que destierra los odios y enemistades, y ahuyenta los vicios que conducen al hombre á la perdición” (La Iglesia, octubre 15 de 1910, p. 581). Los asiduos esfuerzos por el florecimiento de la moralidad cristiana en la clase obrera,

8 Cabe señalar que la socialización consta de una etapa primaria y una secundaria. En la primaria, se delimita la ruta de aprendizaje e inserción a la vida social dentro del ámbito familiar, correspondiéndose a las etapas en las que el niño se relaciona con agentes culturales, los miembros de su familia, que adecuan su comprensión de las normas y valores que implican el vivir en sociedad. Por su parte, la socialización secundaria involucra cualquier aprendizaje posterior que escenifique la asimilación de significados devenidos de otro tipo de instituciones sociales, por ejemplo, la escuela o la Iglesia como entes externos ofrecen al individuo incipientemente socializado nuevos recursos para ampliar el repertorio de respuestas ante las posibles situaciones que enfrente durante su estadía en el campo cultural. El anterior es un claro ejemplo de un proceso de socialización continuo entre las dos fases. La repetición del catecismo en la familia, la iglesia y la escuela posibilitaba estructuras doctrinales fijas en la mente de las nuevas generaciones, haciendo que el ejercicio mecánico de su aprendizaje manipulara directamente la formación de los constructos culturales; de ahí que no sea de extrañar que los marcos identitarios del país tuvieran esquemas de valores profundamente católicos. 
también demandaban la apropiación de la prensa, que imaginada como un cuarto poder', se consideró la responsable de educar, propagar y moralizar las costumbres en las personas de todas las clases sociales.

La figura de la mujer cristiana contribuyó en gran medida a soportar las obras de beneficencia caritativas, y en particular las fiestas navideñas, gracias al legado educativo de las comunidades religiosas llegadas al país, que edificaron el esquema de valores constitutivos del ideal femenino y desempeñaron un papel activo en la reestructuración y movilización de la Iglesia a través de prácticas educativas y de asistencia social. Como ejemplo, la salida de los hermanos hospitalarios de San Juan Dios de la dirección del hospital implicó la llegada de las religiosas francesas pertenecientes a la Congregación de las Hermanas de la Caridad Dominicanas de la Presentación de la Santísima Virgen de Tours ${ }^{10}$, personas idóneas para asumir el reto que representaba la gerencia de la institución hospitalaria. Dicha comunidad era avalada públicamente dada su amplia trayectoria en la administración de los hospitales, asilos y orfanatos franceses, así como en su excepcional manejo de laboratorios y farmacias. De hecho, la congregación francesa fue una de las comunidades abanderadas en el intercambio de saberes no solo respecto al tratamiento de la enfermedad y la pobreza, sino en lo concerniente a la educación femenina del país.

No obstante, y como se estableció atrás, la instrucción de las jóvenes se efectuó formalmente con la iniciación del Monasterio de La Enseñanza en 1783, bajo el amparo de la Orden de la Compañía de María Nuestra Señora, y cuyo proyecto ha llevado desde sus inicios la impronta de la educación como una expresión o dimensión de la caridad cristiana en aras de la dignificación del ser, expandiéndose de manera gradual a través de los siglos XIX y XX por algunas de las principales ciudades y también en determinados lugares apartados del país.

9 Los otros tres poderes son: el Ejecutivo, el Legislativo y el Judicial.

10 Según el Anuario de la Iglesia Católica en Colombia (1957), la congregación fue fundada en 1696 en Sainville (Francia) por la venerable madre Marie Poussepin, cuya causa de canonización fue introducida en el año de 1923. La Congregación es pontificia: fue aprobada por S. S. León XIII en 1887. Su protector es el sumo pontífice Pío XII. Se dedica especialmente a la educación de la juventud, cuidado de los enfermos y alivio de todas las miserias humanas por medio del ejercicio de la caridad (p. 409). 
A esta labor educativa emprendida por la Compañía de María se sumaron los esfuerzos de las hermanas de la Presentación con la fundación de colegios femeninos en el escenario nacional ${ }^{11}$. Sobre el tema, Helg (2001) expone:

Las hermanas de la presentación se convirtieron en la más importante congregación de mujeres en Colombia, no sólo por su número, sino también por su cobertura geográfica y su influencia en la instrucción secundaria femenina; en 1923, dirigían el 24.2\% de los 147 colegios privados de mujeres (p. 80).

Con el tiempo, la extensión de su presencia aseguró el espíritu que cobijó su doctrina, centrado en la consagración a Dios y la perpetuación de los valores católicos en las jovencitas pertenecientes a sectores sociales altos, exaltando el servicio de la caridad, la contemplación y la predicación del Santo Evangelio en un ejercicio práctico de expansión del bien, el servicio a la Iglesia, la educación, la promoción de la juventud y la ayuda a los enfermos y desamparados. De acuerdo con lo anterior, es lógico pensar que sus acciones permearan no solo las instituciones educativas y hospitalarias, sino los asilos, orfelinatos, manicomios, cárceles y casas de corrección, que también fueron centros de participación activa por parte de las hermanas ${ }^{12}$. Para poner de manifiesto los

11 Colombia se convirtió en el primer país de América Latina en donde hizo presencia esta congregación francesa, cuando en la tarde del 21 de junio de 1873 arribaron a Bogotá seis de sus religiosas a petición explícita de don Pedro Navas Azuero, uno de los máximos representantes de la Junta de Beneficencia, quien para entonces desempeñaba sus labores en la sindicatura del Hospital San Juan de Dios. Respaldadas por los más altos dignatarios eclesiásticos, las hermanas abrieron un noviciado en 1875 y cinco años más tarde el primer colegio privado destinado a las niñas de las élites bogotanas; en los años venideros migrarían y se incorporarían numerosas mujeres a la congregación, su crecimiento interno propiciaría la fundación de alrededor de 33 colegios femeninos ubicados en ciudades y pueblos de Cundinamarca, Antioquia, Caldas, Santander, Boyacá, Tolima y parte de la Costa Atlántica.

12 Castro (2014) comenta que en 1874 se hizo un segundo contrato entre las hermanas de la Presentación y la Junta de Beneficencia con respecto a la administración del segundo centro de asistencia social más importante de la región, el Hospicio de Bogotá. En 1879 se firmó el primer contrato entre las hermanas y un representante de una institución estatal diferente a la Junta, se trató de Ezequiel Hurtado, secretario de Guerra y Marina de la Unión, dependencia que funcionaba bajo la responsabilidad del Ministerio de Guerra. En 1883 se firmaron nuevamente dos contratos entre la Junta y las hermanas para la dirección de dos asilos en Bogotá, uno de hombres y uno de mujeres. En 1891 algunas hermanas de la Presentación llegaron a los hospitales de Manizales, Envigado y Santander. En 1903 varias de ellas 
múltiples beneficios que dispensaron sus oficios misericordiosos, el arzobispo Herrera expidió una pastoral con ocasión del quincuagésimo aniversario de su presencia en el país, en ella describe lo siguiente:

Nuestra Patria no ha sido campo impropio para la buena semilla, y la que esparcían con sus virtudes las Hermanas, germinó en las hijas de nuestra católica nación, las cuales sintieron el impulso interior de la gracia que las movía a emplearse en obras mucho más elevadas que las que suelen ser la ocupación de la mujer en el hogar doméstico. No pocas jóvenes pertenecientes a las más notables familias en las ciudades de Colombia, comprendiendo que la nobleza espiritual consiste en el desasimiento de todo afecto mundano y peligroso y en la estrecha unión con Jesucristo, mediante una vida de abnegación y sacrificio, solicitaron y obtuvieron la admisión en la Comunidad religiosa de la Presentación. Más, como la iglesia es católica y herencia del Señor no es patrimonio exclusivo de ninguna clase social, muchas jóvenes de los campos, sencillas, puras, educadas en la fe cristiana y en la práctica de las virtudes, oyeron el llamamiento divino y abrazaron el estado religioso haciendo votos de pobreza, castidad y obediencia para vivir en el ejercicio de la caridad (La Iglesia, junio 30 de 1923, pp. 168-169).

Para la época, es notorio el acogimiento de las virtudes cristianas; la promesa de gracia y salvación atrajo la atención de muchas señoritas que con vocación sublime decidieron socorrer a los más necesitados por medio de su ingreso a la congregación religiosa.

La orientación europea de la asistencia social no contó únicamente con la presencia de las hermanas de la Presentación, fueron muchas las comunidades religiosas que tuvieron una participación destacable en las instituciones sociales del país ${ }^{13}$, por ejemplo, ha de resaltarse el papel de las Hijas de la Caridad

comenzaron a prestar servicios comunitarios en la cárcel de Bogotá. Son vastos los ejemplos de la presencia de la comunidad religiosa en las instituciones de beneficencia a lo largo del siglo XX, así que para este ejercicio solo se nombran algunos ejemplos con los que la autora aborda las relaciones que se establecen entre esta comunidad religiosa y el Estado con relación al desarrollo de la asistencia social en el país.

13 La llegada a Colombia en orden cronológico de las comunidades religiosas que tuvieron relevancia en el campo social fueron las siguientes: Orden de Santa Clara (1573), Orden 
de San Vicente de Paúl ${ }^{14}$, por su influencia en la noción del servicio de caridad hacia los pobres como modo de vida. En 1882 llegaron desde Francia cuatro abnegadas hijas de la caridad para responder al llamado que el Concejo Municipal de Popayán hizo en nombre de los enfermos del hospital de esa ciudad. Las vicentinas, como popularmente se les conoce, iniciaron trabajos el 18 de marzo en la institución hospitalaria "convencidas de que los sacrificios de la obra misionera eran los mismos que acompañaban a los discípulos de Cristo, e impulsadas por su lema 'La caridad de Cristo nos apremia', realizan extraordinarios servicios" (Panqueva y Tamayo, 1981, p. 86).

Poco a poco se fue extendiendo el área de servicio de las religiosas, en 1884 fueron llamadas a dirigir el Hospital de la Caridad de Cali y varias escuelas populares auspiciadas por los fondos del Gobierno departamental. Encontraron allí una tierra próspera y fértil para infundir sus principios morales, la gran acogida que tuvieron por parte de las señoritas de la ciudad hizo que cuatro años más tarde se estableciera el Primer Seminario de las Hijas de la Caridad en Cali. "Desde su llegada a Colombia hasta 1935, las Vicentinas atendieron por lo menos 35 instituciones de asistencia social y 14 colegios femeninos, ubicados principalmente al suroccidente del país, en los departamentos del Valle del Cauca, Cauca y Nariño" (Castro, 2003, p. 36).

Son estas y otras las obras que caracterizaron su estadía en territorio colombiano, todas ellas basadas en el inmenso amor y la profunda fe que heredaron de su fundador, san Vicente de Paúl. El fiel seguimiento de las religiosas

de la Inmaculada Concepción (1538), Religiosas de La Enseñanza (1783), Hermanas de la Caridad de la Presentación (1873), Terciarias Dominicas de Santa Catalina de Siena (1880), Hermanas de la Caridad de San Vicente de Paúl (1882), Madres Bethlehemitas (1885), Hermanitas de los Pobres (1889), Hermanas de la Caridad del Buen Pastor (1890), Orden de la Visitación (1892), Hijas de María Auxiliadora o Salesianas (1897), Hijas de la Sabiduría (1904), Terciarias Capuchinas de la Sagrada Familia (1905), Madres de la Sociedad del Sagrado Corazón de Jesús (1907), Hermanitas de los Pobres de San Pedro Claver (1912) y Carmelitas Descalzas Misioneras (1925). Lo anterior ha sido tomado del cuadro hecho por Castro (2003, p. 26).

14 Según el Anuario de la Iglesia Católica en Colombia (1957), la Comunidad de las Hijas de la Caridad fue fundada en París el 29 de noviembre de 1633 por san Vicente de Paúl, canonizado por el papa Clemente XII el 6 de junio de 1737. Fue cofundadora santa Luisa de Marillac, elevada al honor de los altares el 11 de marzo de 1934 por S. S. Pío XI. La congregación fue aprobada el 8 de junio de 1668 por el papa Clemente IX. Se consagra principalmente a la asistencia de los pobres y enfermos en los hospitales y asilos; se dedica también a las obras escolares, sociales y misioneras. Extendida por el mundo entero, cuenta con más de cuarenta y cinco mil religiosas. 
a las enseñanzas del santo hizo que dirigieran siempre su atención en el auxilio de los más necesitados de ayuda material y espiritual. Lo anterior se estipula de manera explícita en las reglas de la congregación femenina:

El fin principal para el que Dios ha llamado y reunido a las Hijas de la Caridad es para honrar a Nuestro Señor Jesucristo como manantial y modelo de toda caridad, sirviéndole corporal y espiritualmente en la persona de los pobres [...] (Reglas de S. V. P., 1) (citado en Panqueva y Tamayo, 1981, p. 82).

El llamamiento al servicio de Cristo en los pobres se basa en el deseo de santificarlos y salvarlos al hacerlos conocedores de su pertenencia y devenir divino en el Reino de los Cielos, propósitos que encontraron fortaleza en el molde organizativo que la congregación propuso hace varios siglos como apoyo esencial para la comunión y la vida fraterna para con quienes eran objeto de sus servicios. Como antecedente es pertinente decir que las Hijas de la Caridad fueron las primeras en adoptar una renovada idea de congregación basada en la dejación de la vida en aislamiento como parte elemental de su noviciado. La experimentación de nuevos roles propuso que sus funciones permearan activamente la vida pública al hacer de los hospitales, cárceles y casas de los enfermos sus nuevos monasterios. La noción de trabajo colectivo y asistencial que caracterizaba la propuesta, ganó relativa autonomía frente a las tradicionales normas de comportamiento atribuidas a las religiosas, facilitando el ingreso de mujeres con orígenes y culturas diversos al novedoso proyecto.

\section{La escenificación de la caridad en la sociedad civil y su asociación con la celebración navideńa}

En este contexto, la moralización y el mejoramiento de las costumbres eran preceptos abanderados por las mujeres como protagonistas de la acción en el hogar y en la educación, no obstante, el Estado y un importante número de personas pertenecientes a los más distinguidos círculos sociales de las principales ciudades colombianas, manifestaban su caridad con iniciativas benéficas hacia los "pobres", en aras de mitigar en algo sus necesidades básicas. Las sociedades laicas y seculares tenían un papel protagónico allí. Ejemplo de 
las primeras es la Sociedad de San Vicente de Paúl ${ }^{15}$, que desde sus inicios en Bogotá, en 1857, tuvo gran influencia en la educación de los niños pobres. En relación con el segundo grupo de sociedades, estaban las centradas en temas de salud como el Club Noel ${ }^{16}$ en Cali hacia 1924, fecha en la que se creó el Hospital Infantil Club Noel, aún en funcionamiento.

Referidos a la Navidad, los actos benéficos se centraban en la repartición de regalos y vestidos a los nińos pobres; tanto las dos entidades mencionadas anteriormente como otras múltiples organizaciones y personalidades sociales se daban cita en los días que antecedían al 24 de diciembre para cumplir con dicha labor. Al respecto, en la revista El Gráfico (El árbol de navidad, 1910) de Bogotá, se comenta que:

De las fiestas que relacionadas con la conmemoración de $\mathrm{Na}-$ vidad han tenido lugar en este Diciembre para los niños pobres, nos llamó especialmente la atención una que varias damas distinguidas de esta ciudad celebraron á instancias y siguiendo la costumbre anual de la familia Valenzuela. Más de cuarenta niñitas fueron reunidas y largamente obsequiadas no sólo con toda clase de juguetes y baratijas de nochebuena, sino también con trajes y demás prendas de vestir que las mencionadas señoras confeccionan ó acumulan en el curso del año para un día proporcionar alivio de necesidades y regocijo de espíritu á sus pequeñas favorecidas (p. 4).

Durante la primera mitad del siglo XX, la caridad se consolidó como principio básico de las prácticas católicas y las asociaciones laicas que consagraron su vida al servicio de Dios, por lo que la significativa exaltación de las obras benéficas dirigidas al socorro de los pobres en todas las esferas sociales se mantuvo - y se mantendrá, aunque con un sentido diferente-. La influencia del mencionado principio en las festividades navideńas se ilustra perfectamente

15 Los integrantes de la Sociedad para este momento "eran católicos, que se caracterizaron como miembros de la elite local; por ejemplo estaban los ex presidentes Mariano Ospina Rodríguez y Carlos E. Restrepo, aunque también habían profesionales, comerciantes, terratenientes y empresarios" (Morales, 2011, p. 179).

16 El Club fue fundado por la madre Eufemia Caicedo Roa por influencia de su tío, el abogado Jorge Roa, personaje perteneciente a le élite política y económica del país, con el objetivo de intervenir en la realidad de los niños pobres de Cali. A ella se le considera como la fundadora y directora de la Compañía del Niño Dios (Arias, 2013). 
con los muchos ejemplos que se presentan en el ámbito nacional; las dinámicas que componen la naturaleza de tales ejemplos posicionan activamente a la mujer como principal artífice de su desarrollo, la mayoría de ellas pertenecientes a las élites locales. De igual forma, son protagonistas las entidades financieras de diversa índole, puesto que las funciones subsidiarias que socialmente se les confieren se basan en la necesidad de retribuir de alguna manera las riquezas adquiridas, mantener intachable su moral pública y experimentar un regocijo espiritual al dar donaciones como sufragio para sus propias almas.

En Medellín, solo por citar un caso, a comienzos de los años cuarenta del siglo pasado, la Cruz Roja de la América ${ }^{17}$, con el objetivo de continuar con la tradición que implicaba la celebración de la Navidad, hizo entrega de aguinaldos a trescientos nińos y trescientas madres que acudieron al acto que tuvo lugar en la Escuela Cristóbal Colón. Ello fue posible gracias a las acciones de las distinguidas damas del Comité Femenino — presidido por doña Alicia Gómez Nieto-, orientadas a la petición de abonos generosos a varias entidades bancarias, industriales y comerciales. Su éxito fue tal, que muchas de las instituciones colaboradoras prometieron ayudar, además, con una participación de sus balances en la construcción del edificio de la Cruz Roja de la América sobre un terreno de 1200 varas cuadradas, cedido gratuitamente por el municipio (citado en La Cruz Roja de la América, 1943, p. 8).

En el mismo sentido, fueron múltiples los personajes e instituciones que acudieron al llamado caritativo hecho en Navidad. Por su parte, la Iglesia también se constituyó en epicentro de un sinnúmero de eventos benéficos para los pobres. En 1943, en la iglesia de San Benito (Medellín), dirigida por los padres franciscanos, se hizo la gran Fiesta de Santa Isabel ${ }^{18}$ o de los pobres, en donde se pudo apreciar un noble gesto de caridad y abnegación por parte de un grupo de mujeres, que guiadas por la fe trabajaron durante todo el año para obtener un auxilio destinado a completar la obra de socorro que planeaban llevar a cabo. Entendidos como ejercicios espirituales que se hacían con los pobres, se les dieron prendas de ropa y un desayuno a alrededor de

17 Institución de carácter humanitario que hizo presencia en la comuna número 12, La América, de Medellín.

18 Fue llamada la Fiesta de Santa Isabel en honor a las virtudes plasmadas en los cuadros pintados por Montalember de la vida de Isabel de Hungría, puesta por la Santa Iglesia como la patrona de los mendigos, es decir, de aquellos que llamaban a las puertas de los hogares en busca de compasión por su situación de miseria (La fiesta de los pobres, 1943, p. 2). 
mil quinientas personas, entre ellas novecientas mujeres, doscientos cincuenta hombres y sesenta niños que hicieron la primera comunión.

La noticia de la fiesta fue difundida en un periódico local. La nota con la que inició dicha publicación muestra, por sí misma, el constructo de moral pública referido al rol femenino y su vínculo indisoluble con la fe cristiana. Así que, tomada de un "viejo artículo de corte clásico y de alto sabor romántico" reflexiona en torno a lo siguiente:

Desgraciado de aquel que nunca haya creído, que nunca haya amado, que nunca haya abrigado una sola esperanza en el corazón. Creer es vivir, amar es sentir el infinito, y esperar es abarcar la eternidad. El amor hace de todos los hombres un solo corazón y un solo pensamiento. La caridad es la forma poética de ese amor que predica el cristianismo; esa virtud anida con más frecuencia en el corazón de la mujer, porque la mujer socorre, ella abriga con su voz, ampara con los brazos que defienden, con las miradas que atraen, y con toda su alma que se estremece de dolor ante la miseria y aviva el ardor de su caridad para hacer el bien. Jamás implora en vano el mendigo cuando se dirige a una mujer, la mujer es toda sentimiento y corazón, ella tiene caricias y ardorosos besos para el niño que llora en la cuna, ella tiene promesas y consuelos inefables para el hombre infeliz. La mujer tiene constantes cuidados e inagotable ternura para el débil anciano, y el moribundo la verá siempre postrada a la cabecera en su lecho de muerte, teniendo las manos juntas [...] fijos los ojos en el cielo, como un ángel de misericordia que ruega a Dios por el que va a morir. [...] El sacrificio es el triunfo de la mujer, el candor es su fuerza, y la santa caridad la corona de gloria que se ve resplandecer siempre sobre su cándida frente. Ella lucha sin cesar en el mundo para alcanzar la palma de la victoria en el cielo (La fiesta de los pobres, 1943, p. 2).

Se asumen entonces como naturales las funciones de la mujer como educadora, partidaria y veedora de la "buena moral", y la asociación con la Navidad se presenta como la oportunidad perfecta para presentar públicamente actos de compasión por aquellos de quienes se cree que solo pueden ver pasar con vacío y tristeza las festividades decembrinas dada su carencia de ilusión y propósitos para participar en ellas. La cristalización de las socialmente bondadosas obras desemboca en la entrega de aguinaldos como símbolo permeado 
de confraternidad y amor hacia los otros y principalmente hacia Dios, situación que podría ser perfectamente demostrable con la siguiente publicación:

\section{Al Servicio de Dios}

Está alegre la ciudad [Medellín], porque han llegado los días de navidad y en todos los hogares se preparan los niños para recibir juguetes y cantar villancicos en honor del Niño Dios que viene a los pesebres con su mensaje de dulce cariño. Por todas partes vemos desbordar alegría, y unidos a este común sentimiento de júbilo apenas pensamos en lo amable y bueno de la vida. No obstante hay quiénes no tienen hogar, y quiénes están alejados por un deber más alto del fuego de la intimidad, quiénes declinan en un asilo, y quiénes padecen enfermedad e ignominia. A estos también hay quien los ama en el servicio espiritual de Dios, en la caridad sincera y oculta que brota con emoción desde su corazón. Tal es el caso del aguinaldo que lleva la señora doña Eugenia Ángel de Vélez a los conventos, orfanatos, manicomios, hospitales, capillas internados, seminarios y en general a todo el mundo desconocido donde falta la luz sencilla y plena de ternura del hogar. Ella envía, en el silencio de su amor a Dios, para todos sus predilectos, que son los mismos que Cristo prefiere en su misión salvadora, un aguinaldo que va en cajas, en muchísimas cajas, en centenares, con abundancia, con solicitud, con entusiasmo de generosidad. De este modo prolonga en el tiempo la acción de caridad que su Madre le inspiró y enseñó, cuando en su compañía visitaba hogares humildes y extendía su beneficio con fe inmensa en su obra, con espíritu sostenido de socorro y ayuda para los que sufren y esperan en Cristo. Dońa Eugenia Ángel de Vélez, se consagra de este modo, con este aguinaldo, ejemplo perfecto en el servicio de Dios. L. G. (Al Servicio de Dios, 1950, p. 3).

La fuerte recreación de los principios cristianos se entiende como un intento por ilustrar la visión con respecto al ser de la sociedad civil, las virtudes cívicas que debían presentarse en defensa de la moral y la espiritualidad de la población. De modo que aparecen notables personajes de la vida pública y política que escenifican la institucionalización de las prácticas caritativas referidas, precisamente, al festejo navideño. Por ejemplo, para los años que 
siguieron a 1950 era muy común oír hablar de la Navidad del niño pobre, una iniciativa de dońa María Hurtado de Gómez, esposa del presidente Laureano Gómez, y dońa Ana Arboleda de Trujillo Gómez, esposa del alcalde de Bogotá Santiago Trujillo Gómez. La idea consistía en hacer varios festivales en los barrios de las principales ciudades colombianas con el fin de repartir juguetes a los nińos, actividad que contaba con el patrocino de entidades públicas como las alcaldías, las gobernaciones departamentales, la industria, el comercio y algunas damas de sociedad. La acogida que tuvo esta actividad en la escena nacional fue tal que en Barranquilla, por mencionar solo una de las principales ciudades, se instaló en 1950 la Junta de Navidad del Nińo Pobre, precedida por el alcalde, quien manifestó que a su juicio sería necesario dividir la ciudad en varias zonas para facilitar la distribución de los regalos a los niños de cuyas personas estuvieran imposibilitadas económicamente para "hacer llegar a sus hijos esa alegría de Noche Buena" (Instalada la junta de Navidad, 1950, p. 9).

En su momento, y para garantizar la reproducción y funcionalidad de aquella actividad, la misma María Hurtado de Gómez envió una carta dirigida al gobernador del Atlántico unos años después de la instalación de la Junta en Barranquilla, con el objetivo de insinuarle que replicara su iniciativa en todos los municipios que conformaban ese departamento. Parte de aquella carta fue publicada en El Colombiano (1953), periódico de Medellín, con el título "Obsequios de Navidad":

Desearía que, como en años anteriores, se les pudiera dar a los niños pobres de Colombia, algún pequeño obsequio con motivo de las festividades de Navidad. En estos últimos años los Gobernadores colaboraron en forma muy eficaz en este sentido, destinando una partida del presupuesto y dirigiéndose a la vez a los Alcaldes de su dependencia, para que procedieran en igual forma en cada $\mathrm{Mu}-$ nicipio, y de acuerdo con el Párroco. - Mucho agradecería a usted se sirviera atender esta insinuación y desarrollarla como mejor crea conveniente. Y permítame que le manifieste que en estos asuntos sociales y de caridad, las señoras prestan magnífica colaboración, lo mismo que las empresas, Bancos y casas comerciales (p. 12).

La respuesta a su petición fue favorable, dado que el gobernador manifestó dirigirse inmediatamente a las instituciones correspondientes (alcaldes a su cargo, sacerdotes, industrias y casas de comercio) para desarrollar la iniciativa, expresando un notable agradecimiento al declarar: "Será mucho mayor el 
número de hogares pobres que en la próxima Nochebuena recibirán en este Departamento la visita del Niño Dios y con ella un poco de felicidad para los niños que más estén necesitados de ella" (Obsequios de Navidad, 1953, p. 12). Paralelo a aquel acto, se resalta la entrega de aguinaldos, ropa y comida a ochenta mil niños bogotanos por parte de la primera dama de la nación el 23 de diciembre del mismo ańo, con ayuda pecuniaria de los Gobiernos nacional, departamental y municipal, la banca, la industria y el comercio. Algunos de estos fueron distribuidos a varias instituciones de la siguiente manera:

Para los centros de higiene 4.000; Dirección de Aseo 3.000; Padres Eudistas 335; Parroquia de Santa María de los Ángeles 12; Padre Rochereau 388; Hermanas de la Asunción 350; Escuela Modelo 200; Madres Vicentinas 302; Hogar del Niño 220; Hermanas de Santa Ana 80; Veracruz 150; Hermanas de San Juan 250; Hermanas del barrio de La Libertad 195 (80.000 Niños recibirán aguinaldo, 1950, p. 9).

Al respecto habría que resaltar que las contribuciones hechas por las entidades gubernamentales para la compra de dichos aguinaldos eran sumamente generosas ${ }^{19}$, muestra de ello es la donación de diecisiete mil pesos por parte de la Alcaldía de Bogotá para esta tarea, que fue llevada a cabo en la instalación de un árbol de Navidad en la ciudad, iniciativa que formaba parte de las actividades de la Navidad del Niño Pobre. Asimismo, la Gobernación de Cundinamarca contribuyó con la actividad dando a sus voceras cinco mil pesos para su realización, y en menor cantidad apoyaron el Ministerio de Higiene, el Ministerio de Hacienda y Crédito Público y la Caja de Crédito Agrario con dos mil pesos cada uno. En el caso de las instituciones bancarias y financieras, los aportes oscilaron entre veinticinco y mil pesos; entre los donantes se encontraban el Banco de la República, Colombiana de Tabaco, Suramericana de Seguros, Bavaria, la Federación Nacional de Cafeteros, la Empresa Colombiana de Curtidos, la Compañía Colombiana de Gas, el Jockey Club, la Asociación Nacional de Industriales, Avianca, la Fábrica de Galletas Noel, entre otros (citado en Donaciones para el Árbol, 1950, p. 13).

19 Se alude a la amplitud en la generosidad de las considerables sumas de dinero donadas por las entidades teniendo en cuenta que el salario mínimo para la época era de sesenta pesos. 
Traer a colación estos hechos tiene como propósito ilustrar el imaginario público de la mujer como contenedora de las virtudes cristianas — caridad, compasión y misericordia - socializadas en la familia, la educación y la iglesia, que cristaliza su acción al tratamiento de la pobreza y la noción de "bienestar común”. Esto en concordancia con el imaginario cultural que englobaba los principios morales alrededor de todo aquello que enaltecía a la familia. La mujer cristiana, veedora de la educación correcta y las buenas costumbres, debía crecer en honradez, y el campo socialmente estipulado para lograr tal hazaña sin duda alguna era la beneficencia pública, a través de acciones que impulsaban el bien.

Este contexto demuestra la persistencia y el profundo arraigamiento del esquema de valores y creencias cristianas, situación que fue plataforma para la anidación y permanencia de la Novena al permitirle su adaptabilidad a las exigencias contemporáneas de moral y buenas costumbres, por lo que a continuación se explicará la capacidad del texto para renovarse, acomodarse y seguir difundiéndose en el territorio y extendiéndose en el tiempo. 